\title{
Occult Spontaneous Ocular Perforation Presenting as Conjunctival Chemosis in a Patient with Marfan's Syndrome
}

\author{
Nafsika Voulgari Clarice Giacuzzo Ann Schalenbourg \\ George D. Kymionis \\ Department of Ophthalmology, University of Lausanne, Jules-Gonin Eye Hospital, \\ Fondation Asile des Aveugles, Lausanne, Switzerland
}

\section{Keywords}

Occult ocular perforation - Conjunctival chemosis · Marfan's syndrome

\begin{abstract}
We report a case of occult spontaneous ocular perforation presenting as conjunctival chemosis in a patient with Marfan's syndrome (MFS). A 38-year-old female with MFS presented with bilateral conjunctival chemosis since 6 months. Best-corrected visual acuity was 20/20 in both eyes. On slit-lamp examination, a diffuse conjunctival chemosis was observed in both eyes without any signs of ocular hypotony (decreased visual acuity, low intraocular pressure, shallow anterior chamber, pupil distortion, hypotony maculopathy, and chorioretinal folds). Anteriorsegment optical coherence tomography revealed a corneoscleral fistula at the left nasal limbus, without any similar finding in the right eye. A scleral patch was performed at the site of the perforation. At 3 month's follow-up, the left chemosis had regressed, with a stable best-corrected visual acuity in both eyes. However, on ultrasound biomicroscopy, another fistula at the right superior limbus was found, and the patient was referred for treatment with a scleral patch. In conclusion, conjunctival chemosis in a patient with MFS should raise the suspicion of an occult spontaneous ocular perforation.




\section{Case Reports in Ophthalmology}

\section{Introduction}

Marfan's syndrome (MFS) is the second most common autosomal dominant connective tissue disorder after osteogenesis imperfecta with an estimated incidence between 1/5,000 and 1/20,000 [1]. It affects the cardiovascular, musculoskeletal, and ocular system, the latter being involved in approximately $80 \%$ of all MFS patients, with the most common finding being ectopia lentis. Mutations in the fibrillin-1 gene (FBN1) account for the ocular manifestations of MFS. Scleral thinning is also frequently observed in MFS though rarely complicated by scleral perforation [2-7]. To our knowledge, this is the first report of conjunctival chemosis as the presenting sign of an occult spontaneous ocular perforation in a patient with MFS.

\section{Case Presentation}

A 38-year-old female with MFS presented with bilateral swelling since 6 months, which was unresponsive to antiallergic or steroid treatment. An uncomplicated pars plana lensectomy for ectopia lentis had been performed 26 years earlier in both eyes, and an intraocular lens (IOL) exchange for post-traumatic IOL subluxation in the right eye (RE) 23 years before. In the left eye (LE), she had been subjected to an IOL exchange and anterior vitrectomy for IOL subluxation 16 years earlier, followed by an IOL exchange with pars plana vitrectomy for IOL subluxation 11 years before the actual presentation. Best-corrected visual acuity was 20/20 in both eyes (OD: $-0.75-2.75 \times 17$, OS $-0.50-3.50 \times 124$ ). Intraocular pressure (IOP) was 17 $\mathrm{mm} \mathrm{Hg}$ in the RE and $14 \mathrm{~mm} \mathrm{Hg}$ in the LE. On slit-lamp examination, a diffuse bilateral conjunctival chemosis adjacent to the limbus was present, without any conjunctival redness. The corneas were clear with a deep and quiet anterior chamber (AC). Both intraocular lenses were well centered in the posterior chamber (Fig. 1). Fundus evaluation was unremarkable without any signs of a hypotony maculopathy nor any angioid streaks in both eyes. Anterior-segment optical coherence tomography (AS-OCT) of the LE revealed a corneoscleral fistula draining to the subconjunctival space at 9 o'clock (Fig. 2a), without any similar finding in the RE. The left scleral defect was treated with a scleral patch. At 3 months' follow-up, the LE chemosis had regressed, IOP was $10 \mathrm{~mm} \mathrm{Hg}$ and $17 \mathrm{~mm} \mathrm{Hg}$ in the RE and LE, respectively. The lowering in the right IOP induced us to require a detailed ultrasound biomicroscopy (UBM) that demonstrated a channel between the AC and the subconjunctival space at 12 o'clock, as well as an area of scleral thinning close to the 8 o'clock limbus (Fig. 2b). Scleral reconstruction was scheduled for the RE.

\section{Discussion}

In this report, we describe an MFS patient with conjunctival chemosis as the presenting sign of an occult spontaneous ocular perforation. Scleral thinning is a common ocular feature in MFS patients and is attributed to the presence of abnormal fibrillin between the collagen lamellae of the sclera [1]. Scleral perforation in MFS patients has been described following trabeculectomy and scleral buckling procedures [2-7]. Moreover, scleral wound dehiscence can be encountered several years after lensectomy for ectopia lentis in MFS [7]. Nevertheless, in these cases, patients presented with redness and tearing [6-7], decreased vision [3-5], or progressive myopia [5] while all of them showed signs of ocular hypotony such as a low IOP, 
shallow AC, pupil distortion, or hypotony maculopathy. Our patient presented with conjunctival chemosis as the first sign of occult spontaneous ocular perforation.

Though chemosis was bilateral at presentation, AS-OCT did not allow us to immediately identify the RE scleral defect. As UBM was not performed initially, this observation either highlights the superiority of the UBM over AS-OCT (acoustic wavelength vs. optical wavelength) in diagnosing scleral perforation or can be explained by the fact that the defective sclera can leak without visible rupture.

Scleral perforation in MFS has been treated with a scleral patch graft or suturing $[3,4,6]$. Alternatively, autologous conjunctival epithelium transplantation combined with a scleral patch [7] and the combination of scleral homograft and amniotic membrane transplant [2] have also been proposed with encouraging results. In one case, recurrent scleral rupture after surgical repair has been described adjacent to the previously treated area [4].

In conclusion, occult spontaneous ocular perforation can present as conjunctival chemosis in MFS patients. The diagnosis can be challenging, and a high index of suspicion is, therefore, warranted in these patients. Prompt recognition, close long-term follow-up, and patient education are critical for the prevention of hypotony-related complications.

\section{Statement of the Ethics}

Written informed consent for this case report was obtained from the patient.

\section{Disclosure Statement}

The authors declare that there are no conflicts of interest to disclose.

\section{Funding Sources}

This research received no specific grant from any funding agency in the public, commercial, or not-for-profit sectors.

\section{Author Contributions}

N.V.: writing and reviewing.

C.G.: writing and reviewing.

A.S.: writing and reviewing.

G.D.K.: reviewing.

\section{References}

1 Nemet AY, Assia EI, Apple DJ, Barequet IS. Current concepts of ocular manifestations in Marfan syndrome. Surv Ophthalmol. 2006 Nov-Dec;51(6):561-75.

2 Rodríguez-Ares MT, Touriño R, Capeans C, Sánchez-Salorio M. Repair of scleral perforation with preserved scleral and amniotic membrane in Marfan's syndrome. Ophthalmic Surg Lasers. 1999 Jun;30(6):485-7.

3 Deramo VA, Haupert CL, Fekrat S, Postel EA. Hypotony caused by scleral buckle erosion in Marfan syndrome. Am J Ophthalmol. 2001 Sep;132(3):429-31. 


\section{Case Reports in Ophthalmology}

4 Turaga K, Senthil S, Jalali S. Recurrent spontaneous scleral rupture in Marfan’s syndrome. BMJ Case Rep. 2016 May;2016:bcr2016214764.

5 Sharifipour F, Panahi-Bazaz M, Malekahmadi M, Takhtaeian A. Spontaneous Scleral Perforation and Optic Nerve Dural Ectasia in Marfan Syndrome. Iran J Ophthalmol. 2013;25(2):167-70.

6 Law RWK, Tang WWT, Lai JSM. Bilateral spontaneous scleral perforation in Marfan's syndrome. Asian J Ophthalmol. 2006;8:110-2.

7 Mancino R, Aiello F, Ceccarelli S, Marchese C, Varesi C, Nucci C, et al. Autologous conjunctival epithelium transplantation and scleral patch graft for postlensectomy wound leakage in Marfan syndrome. Eur J Ophthalmol. 2012 Sep-Oct;22(5):830-3.
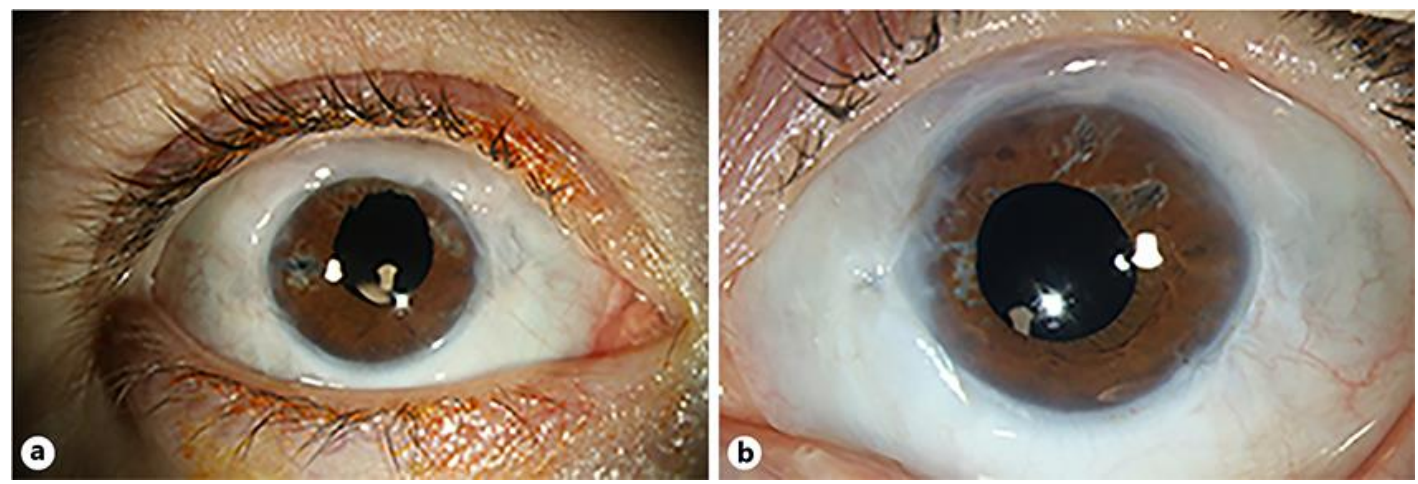

Fig. 1. Slit-lamp photograph of the RE (a) and LE (b) demonstrating diffuse conjunctival chemosis. 


\section{Case Reports in Ophthalmology}

\begin{tabular}{l|l}
\hline Case Rep Ophthalmol 2019;10:344-348 \\
\hline DOI: 10.1159/000503440 & $\begin{array}{l}\text { @ 2019 The Author(s). Published by S. Karger AG, Basel } \\
\text { www.karger.com/cop }\end{array}$ \\
\hline
\end{tabular}

Voulgari et al.: Occult Spontaneous Ocular Perforation Presenting as Conjunctival Chemosis in a Patient with Marfan's Syndrome
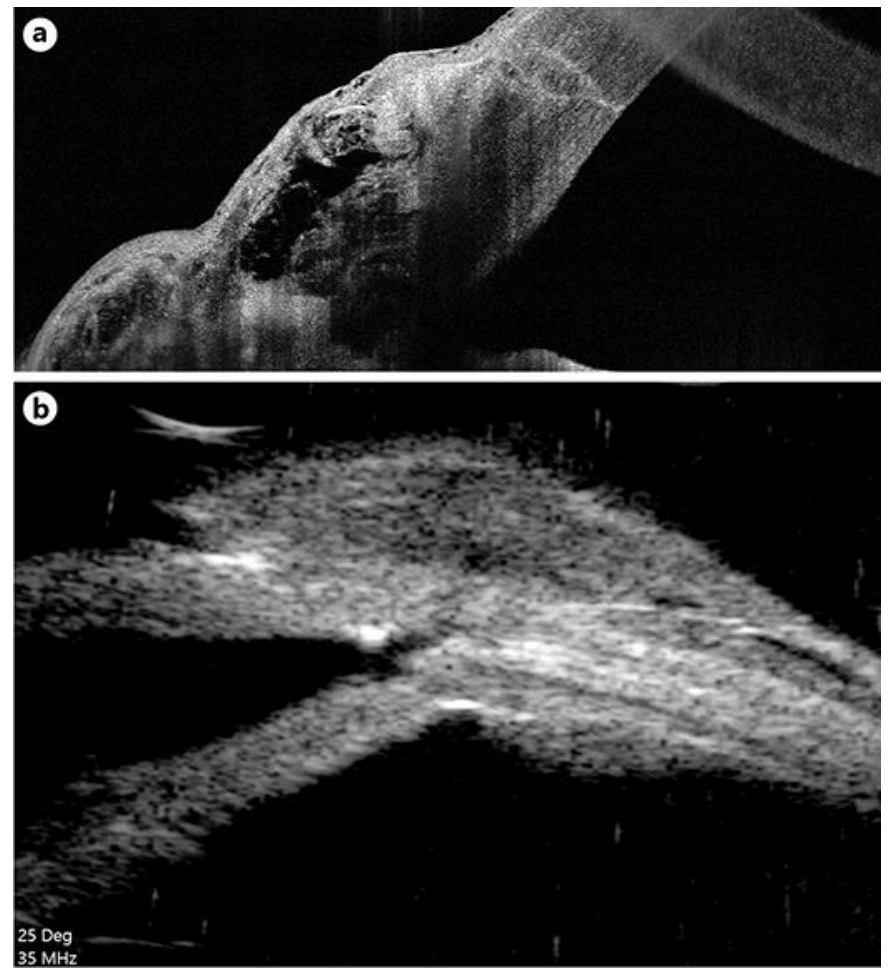

Fig. 2. a AS-OCT of the LE showing the corneoscleral fistula draining to the subconjunctival space. $\mathbf{b}$ UBM of the RE revealing the presence of a channel between the $\mathrm{AC}$ and the subconjunctival space. 